\title{
CYCLOHEXANE - PHENOL BINARY LIQUID MIXTURE: BEHAVIOR AND PARAMETERS AT CRITICAL CONDITIONS
}

\author{
Iyad Saadeddin*, Ghadeer Hussein, Issam R. Abdelraziq \\ Department of Physics, An Najah National University, Nablus, Palestine. \\ *corresponding author e-mail: iyads@ @ajah.edu
}

\begin{abstract}
A new liquid binary cyclohexane - phenol mixture was prepared. The dynamic shear viscosity coefficients of this liquid mixture, for different phenol concentrations and temperatures, were investigated by capillary viscometer made from glass. The dynamic shear viscosity showed an anomaly close to the critical temperature $T_{c}=17.0^{\circ} \mathrm{C}$. The anomaly behavior was observed at critical weight concentration of phenol, $x_{c}=2.70 \%$. At temperatures above critical one, the experimental data were fitted using mode Coupling Theory. It was found that the dynamic shear viscosity non-critical background had a value of $\eta_{0}=0.8174$ $c P$. Also, using a pycnometer of $10 \mathrm{ml}$, density measurements were performed. The expected law for mass density above critical temperature was the power law. The noncritical mass density part was found to have a value of $\rho_{0}=0.7357 \frac{\mathrm{gm}}{\mathrm{cm}^{3}}$. In addition, The isobaric thermal expansion coefficient at critical temperature $\left(\alpha_{p c}\right)$ was also deduced and found to have a value of $2.07 \times 10^{-6}{ }^{\circ} \mathrm{C}^{-1}$. Finally, the derivative of critical temperature with respect to pressure $\left(T_{c}{ }^{\prime}\right)$ was found to have a value $1.22 \times 10^{-4} \frac{\mathrm{K}}{\mathrm{Pa}}$.
\end{abstract}

\section{KEYWORDS}

Viscosity, Mode coupling theory, Liquid binary mixture, Power law, Critical parameters.

\section{INTRODUCTION}

Due to their unusual behavior, the understanding the theoretical background of liquid-liquid mixture is very important for scientific and applied knowledge [1]. For these mixtures, The knowledge of their physicochemical properties are important for many chemical industrial processes. In industries, which involves physicochemical processes, mixtures are commonly used to handle the mixtures of alcohols, ketones, hydrocarbons, and aldehydes [2].

Cyclohexane and phenol are well known to be hazardous materials [3]. They are widely used in different industries. Due to that, it is highly crucial to identify their physico-chemical properties. Also, for understanding transport properties under heat and fluid flow, The physical properties for pure materials and their binary mixtures at different temperature range and different composition rates are important to identify.

\subsection{Binary Mixtures And Liquids}

A mixture of two unlike liquids is usually called binary mixtures; when they mixes homogeneously, the mixture has characterization at a critical concentration and critical 
temperature. However, at temperatures and concentrations differ from those at critical, the two liquids do not mix homogeneously, and there will be a well-defined two phases. Examples of binary mixtures are nitrobenzene - n-hexane, methanol - cyclohexane, and benzene - coconut oil [4].

\subsection{Literature Review}

Many studies related to a wide range of binary liquid mixtures have been done by many researchers. They have used many types fitting for equations and polynomials to explain their results for different liquid parameters, like density, viscosity, etc.

The behavior of shear viscosity in the critical region for a binary mixture of different liquids goes back first to Fixman. In the critical mixing region, Fixman's approach described the mixtures rise in viscosity in due to the velocity gradient that exist of in the critical region [5]. Domanska and Krolikowska found the correlations between viscosities and densities when they mixes five different ionic liquids with water. They found that their results of density, viscosity, and excess molar volume, were in correlations with Redlich-Kister equation, polynomials of the second order, and VFT equation [6]. AJ Easteal measured the tracer diffusion coefficients of the binary mixtures of tritiated water and acetonitrile at several temperatures., The diffusion data were used to test a semi-empirical correlation between self-diffusion coefficients and solution viscosity [7]. Ultrasonic sound speed, viscosities, and densities of p-chloroacetophenone, pmethylacetophenone, and pure propiophenone and their binary mixtures prepared using a common component of $\mathrm{N}, \mathrm{N}$-dimethylaniline were measured for all composition range at $308.15 \mathrm{~K}$ and $303.15 \mathrm{~K}$ [8]. M. Emila et al. measured the dynamic viscosities of four binary mixtures at Kelvin $(\mathrm{K})$ temperatures of 303.15 , 308.15, 313.15, 318.15and 323.15 under atmospheric pressure. The deviations of viscosity for the binary mixtures were fitted using polynomial equation "Redlich-Kister" [9]. The temperature dependent shear viscosity for the nitrobenzene and n-heptane binary liquid mixture was measured by the group of Abdelraziq. They detect The viscosity anomaly at different concentration and temperature. The mode coupling theory was used to analyze the results above the critical temperature [10]. Kestin Josephet al. studied the kinematic and dynamic viscosities for different aqueous solutions; They tabulated values of kinematic and dynamic viscosity of solutions from potassium chloride in a temperature of 20-150 ${ }^{\circ} \mathrm{C}$ range, pressure of 0.1-30 MPa range and molal concentration range of 0-5.4 [11]. Sk. Fakruddin Babavali et al. studies ultrasonic velocities, viscosities and densities in binary liquid mixtures containing heterocyclic aromatic compound quinoline with 1-butanol have been measured at temperatures $\mathrm{T}=(303.15,308.15,313.15$ and 318.15$) \mathrm{K}$ over the entire mole fraction range of quinoline [12]. Ahlam et al. show that the viscosity Arrhenius-type equations for pure liquids can be extended to binary liquid mixtures [13].

\subsection{Study Objectives}

Investigate critical $(\eta)$ and noncritical background $\left(\eta_{0}\right)$ of shear viscosity by applying the approach of mode coupling theory. Also, determining the Isobaric specific heat $\left(\mathrm{c}_{\mathrm{pc}}\right)$ at critical conditions and the thermal expansion coefficient $\alpha_{\mathrm{p}}$ at constant pressure (isobaric). In addition, Calculating the derivative of critical temperature with respect to pressure $\left(\mathrm{T}_{\mathrm{c}}{ }^{\prime}\right)$. Moreover, For binary mixture above near critical temperature and at critical concentration, power law will be set up to describe the mass density behavior as a function of temperature. 


\section{THEORETICAL BACKGROUND}

Viscosity is defined as liquid internal friction when it is set in motion. hence, fluid has tendency to resist its flow. On the microscopic level, viscosity depends on molecular interactions and hence it is related to the way of diffusion for molecules. The fluidity that measures the fluid layers mobility is the opposite of the viscosity [14-15].

\subsection{Shear Viscosity Close To Critical Point}

Perl and Ferrell approach of mode coupling theory predicts the shear viscosity anomaly at critical conditions (temperature and concentration) [16]. At the critical concentration, the shear viscosity $\eta$ depends on temperature $\mathrm{T}$ as $\mathrm{T}$ approaches $\mathrm{T}_{\mathrm{c}}$, where the increase in nis indefinitely. The power law , considered for the resulting singularity, is given by [17]:

$\eta=\eta_{0} \tau^{-x_{\eta} v}(1)$

where $\eta_{0}$ is the dynamic shear viscosity noncritical background, $\tau=\frac{T-T_{c}}{T_{C}}$ is the absolute reduced temperature and $x_{\eta}$ and $v\left(v=0.64, x_{\eta} v=0.04\right)$ are the critical exponents.

Note that the critical exponents values depend on very general properties, such as microscopic interactions range and dimensionality of in the system. this was observed by many workers where they found same critical exponent for completely different systems [18-20].

\subsection{Power Law}

A critical exponents set are used to describe the binary mixture singular behavior around the critical point. The non-analyticity of different thermodynamic functions is described by exponents describe. In the asymptotic regions, very close to the critical point, depending on the approached thermodynamic path, Thermo-physical quantities reveal a typical behavior of power-law.

Many important thermodynamic properties are associated with mixtures critical points; some properties of thermodynamics diverge approaching $T_{c}$ with power-law divergence in $\left|\mathrm{T}-\mathrm{T}_{\mathrm{c}}\right|$ close to critical region, whereas a non-divergent power-law is shown for some other thermodynamic properties. The called critical exponents is given for exponents that go with these power laws [21].

Above critical temperature and at critical concentration $\mathrm{x}_{\mathrm{c}}$, the mass density was given by the temperature $(\tau)$ dependent power law as given for viscosity [17]:

$\rho=\rho_{0} \tau^{-x_{\rho} v}$

Where $v=0.64$ and $x_{\rho} v$ is critical exponents.

\subsection{Two - Scale -Factor Universality}

In phase transition study, The two-scale-factor universality has played a central role in predicting the liquid binary mixture critical phenomena [22]. The two-scale-factor universality was defined by: 
$R_{\xi}=\xi_{\mathrm{o}}\left(\frac{\alpha_{\mathrm{c}} \mathrm{c}_{\mathrm{pc}}}{\mathrm{K}_{\mathrm{B}}}\right)^{\frac{1}{d}}=\xi_{\mathrm{o}}\left(\frac{\alpha \mathrm{T}_{\mathrm{c}} \alpha_{\mathrm{pb}}}{\mathrm{K}_{\mathrm{B}} \mathrm{T}_{\mathrm{c}}}\right)^{\frac{1}{\mathrm{~d}}}=0.270(3)$

where $\xi_{0}$ is the critical amplitude of correlation length, $\propto=0.11$ is the critical universal exponent quantity, $T_{c}$ is the critical temperature, $\rho_{c}$ is the mass density is at $T_{c}, c_{p c}$ is the critical specific heat (isobaric), $K_{B}$ is Boltzmann's, $\alpha_{p b}$ is the critical thermal expansion (isobaric), $\mathrm{T}_{\mathrm{c}}{ }^{\prime}=\frac{\mathrm{dT}_{\mathrm{c}}}{\mathrm{dP}}$ is the derivative of critical temperature with respect to pressure along the critical line, and $d$ is the dimension of the considered space.

The isobaric critical specific heat can be found from the isobaric specific heat formula [23]:

$\mathrm{c}_{\mathrm{p}}=\mathrm{c}_{\mathrm{pc}} \tau^{-\propto}+\mathrm{c}_{\mathrm{pb}}(4)$

Where $c_{p c}$ is the isobaric critical specific heat, the reduced absolute temperature is $\tau=\frac{T_{-}-T_{c}}{T_{c}}, c_{p b}$ and is the specific heat background at constant pressure, and $\propto$ is the critical exponent.

The isobaric critical thermal expansion coefficient can also be found from [23]:

$\alpha_{\mathrm{p}}=\alpha_{\mathrm{pc}} \tau^{-\propto}+\alpha_{\mathrm{pb}}(5)$

Where $\alpha_{\mathrm{pb}}$ is the background term, and $\alpha_{\mathrm{pc}}$ is the isobaric critical thermal expansion coefficient. Thermal isobaric expansion coefficient can be expressed also by [24];

$\alpha_{p}=\rho\left(\frac{d \rho^{-1}}{d T}\right)(6)$

Using equation (6), $\alpha_{p}$ can be determined, where $\left(\frac{\mathrm{d} \rho^{-1}}{\mathrm{dT}}\right)$ is the slope of the linear fit for $\rho^{-1}$ versus temperatures $\mathrm{T}\left({ }^{\circ} \mathrm{C}\right)$ graph. $\alpha_{p}$ at each temperature can then be calculated by multiplying the slope with the density.

\section{Experimental Procedure}

Purified Phenol (99.90 \%) and Cyclohexane (99.60\%), purchased from Sigma-Aldrich Co., were used to prepare the binary mixture under ambient conditions. the specifications for cyclohexane and phenol are shown in table 1

Table 1. Cyclohexane and phenol chemical and physical and properties.

\begin{tabular}{|c|c|c|}
\hline Property & Cyclohexane [25] & Phenol [26] \\
\hline Molecular weight $\left(\mathrm{gm} . \mathrm{mol}^{-1}\right)$ & 84.2 & 94.111 \\
\hline Physical state at $20^{\circ} \mathrm{C}$ & Liquid (Colorless) & Crystalline solid (Colorless) \\
\hline Density at $20^{\circ} \mathrm{C}\left(\mathrm{gm} / \mathrm{cm}^{3}\right)$ & 0.7785 & 1.0710 \\
\hline Melting point $\left({ }^{\circ} \mathrm{C}\right)$ & 6.47 & 40.9 \\
\hline Boiling point $\left({ }^{\circ} \mathrm{C}\right)$ & 80.7 & 181.8 \\
\hline Viscosity at $20^{\circ} \mathrm{C}(\mathrm{cP})$ & 1.0 & $8.28 \times 10^{4}$ \\
\hline Water solubility at $20^{\circ} \mathrm{C}(\mathrm{mg} / \mathrm{L})$ & 55 & 0.35 \\
\hline Vapor pressure at $20^{\circ} \mathrm{C}(\mathrm{mmHg})$ & 97 & \\
\hline
\end{tabular}




\subsection{Sample Preparation}

A total $10 \mathrm{ml}$ volume $\mathrm{V}$ of Cyclohexane - phenol binary liquid mixtures were prepared. To prepare phenol liquid, phenol solids were dissolved into cyclohexane liquid which has volume V. Because cyclohexane mass density is lower than phenol, Cyclohexane liquid was always on the top of the liquid binary mixture, whereas the phenol liquid was in the bottom. The weight concentration of phenol ( $\mathrm{x}_{\text {phenol }}$ ) in the mixture was ranges from $2.00 \%$ to $40.00 \%$. In a given sample of volume $\mathrm{V}$ prepared from liquid mixture of cyclohexane - phenol, $\mathrm{x}_{\text {phenol }}$ can be calculated using:

$\mathrm{X}_{\text {phenol }}=\frac{\rho_{\text {phenol }} \mathrm{V}_{\text {phenol }}}{\rho_{\text {phenol }} \mathrm{V}_{\text {phenol }}+\rho_{\text {cyclohexane }} \mathrm{V}_{\text {cyclohexane }}}(7)$

\subsection{Sheer Viscosity}

Viscometer (U-shaped glass tube) was used for shear viscosity measurements for different cyclohexane - phenol mixture prepared at different phenol concentrations. Liquid viscosity standard by Brook field Engineering Laboratories Inc. was used to calibrate measurements of viscosity. For each prepared sample, during viscosity measurements, the temperature was changed between $14.0{ }^{\circ} \mathrm{C}$ and $21.0^{\circ} \mathrm{C}$. During measurements, the temperature was controlled using refrigerated and heated circulator (model Julabo F25-MV).

\subsection{Density Measurements}

Using $10 \mathrm{ml}$ pycnometer, The cyclohexane - phenol density has been measured at different temperatures. The density was calculated from the mixture mass in the pycnometer volume ( 10 $\mathrm{ml}$ ). Because of density sensitivity for temperature, different concentration binary mixtures were prepared under same temperature. This was done in situ during density measurements.

Initially, As a reference densities, cyclohexane liquid and phenol liquid densities were measured at room temperature. A density of $0.7647 \frac{\mathrm{gm}}{\mathrm{cm}^{3}}$ and $1.0476 \frac{\mathrm{gm}}{\mathrm{cm}^{3}}$. was measured for pure cyclohexane liquid and pure phenol liquid respectively.

\section{RESULTS AND ANALYSIS}

\subsection{Critical Temperature And Concentration}

Dynamic viscosity variation with temperature for different phenol concentrations (from $2.00 \%$ to $13.20 \%$ ) by weight plotted in Fig. 1. As the temperature increases, the viscosity was found to decrease. Increasing temperature increases the dynamic motion of liquid molecules due to thermal energy, this will lead to decrease the intermolecular forces (cohesive force) between liquid molecules. Hence, the viscosity of the liquid decreases making the liquid molecular layers to slide over each other more easily [27]. Also, as seen from Fig. 1, The viscosity was found to increases with phenol concentration. This was expected because phenol has higher viscosity than cyclohexane (see table 1) and increases phenol's concentration will lead to increase the mixture viscosity. Same behavior was observed for the phenol concentrations above $13.20 \%$, both phenol and cyclohexane liquids showed two separated liquids in the same measuring temperature range; the viscosity was also observed to decrease with temperature and increase with phenol concentration. This indeed due to the same reason discussed above. 


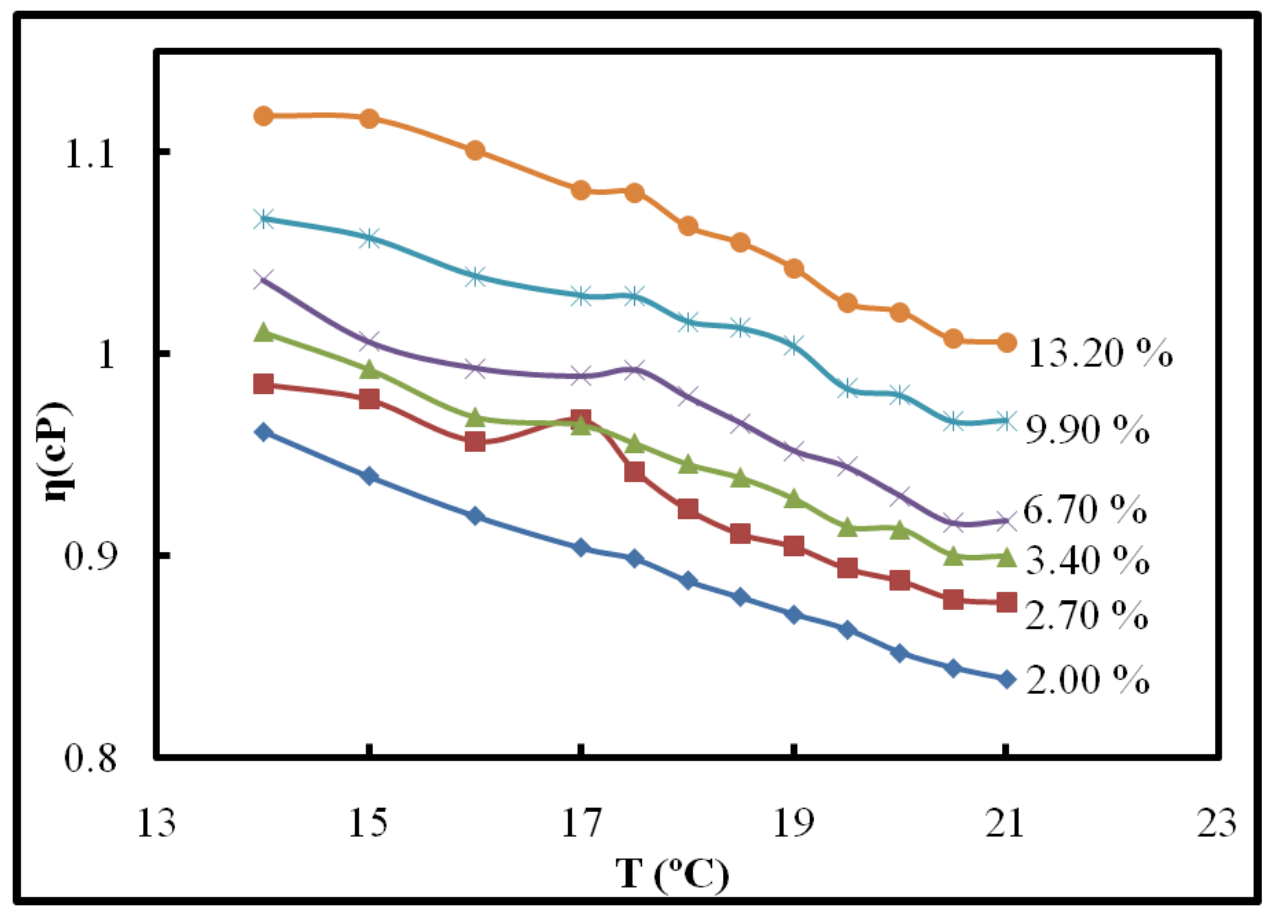

Figure 1. Cyclohexane - phenol dynamic viscosity versus temperature for different phenol weight concentrations.

As also observed in Fig. 1, the graph has an anomaly behavior at temperature of $17{ }^{\circ} \mathrm{C}$. This anomaly was observed for phenol concentration of $2.7 \%$ in the binary liquid mixture. In addition, at this temperature $\left(17{ }^{\circ} \mathrm{C}\right)$ and concentration $(2.7 \%$ of phenol), the binary liquid mixture becomes undistinguishable because it transforms from two phases to one phase. Therefore, for both observed temperature and concentration, one can consider this point to be the critical point for the liquid binary mixture of cyclohexane-phenol. Moreover, at this critical point, the measured Shear viscosity was $0.9672 \mathrm{cP}$. The viscosity observed at critical point is closed to that of cyclohexane (see table 1). Indeed, this was expected because cyclohexane concentration constitute $97.3 \%$ of the mixture, and hence it's viscosity will be dominant in the mixture.

\subsection{The Noncritical Background Of Dynamic Shear Viscosity}

At the critical concentration, dynamic sheer viscosity is temperature dependent power law. At critical concentration, the dynamic sheer viscosity was measured at a temperature ranges from $17.1^{\circ} \mathrm{C}$ to $21.0^{\circ} \mathrm{C}$. The selected range of temperature was because power law is valid at temperatures when they are close to $T_{c}[17,21]$. Using linear form of equation (1), which is represented by the following equation:

$\ln (\mathrm{\eta})=\ln \left(\mathrm{\eta}_{\mathrm{o}}\right)-x_{\mathrm{\eta}} v \ln (\tau)(8)$

$\ln (\eta)$ versus $\ln (\tau)$ was drawn and linearly fitted (Fig. 2) to find the critical exponent value of $x_{\eta} v$. The linear equation of the fit is shown in the inset. 


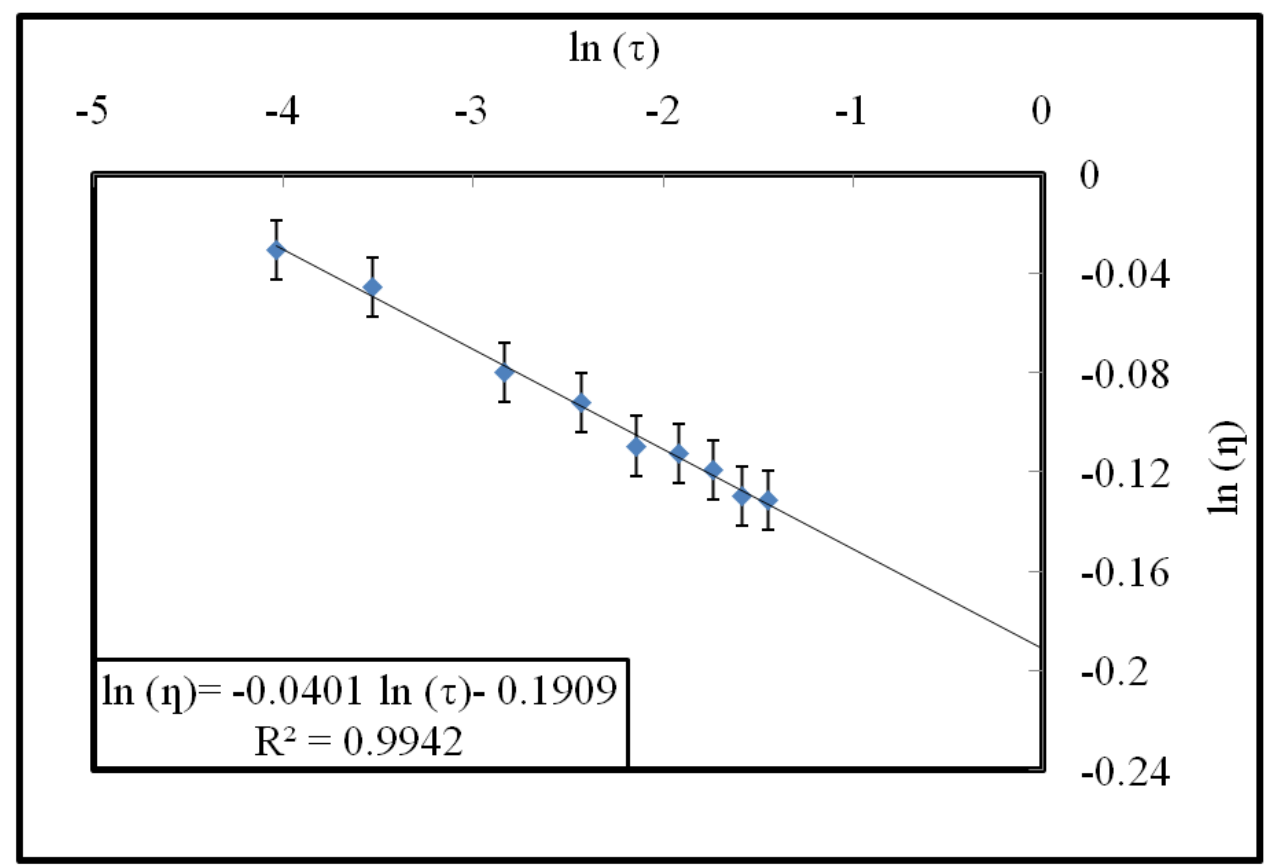

Figure $2 . \ln (\eta)$ vs. $\ln (\tau)$ for cyclohexane - phenol mixture at critical concentration above the critical temperature. Linear equation for fitted data is shown in the insert.

From the slope of the linear fit, critical exponent for the cyclohexane-phenol critical mixture was found to be equals to 0.0401 . This result is in a full accordance with the critical exponent observed at critical concentrations [17]. This confirms that the cyclohexane-phenol binary mixture belongs to a class of binary mixtures that fit power law at critical concentration near critical temperature.

The noncritical shear viscosity part $\left(\mathrm{\eta}_{\mathrm{o}}\right)$ can be found from the linear fit intercept $\left(\ln \left(\mathrm{\eta}_{\mathrm{o}}\right)=\right.$ $-0.1909)$. The calculated noncritical shear viscosity part was $0.8262 \mathrm{cP}$. The sheer viscosity $(0.9762 \mathrm{cP})$ at critical conditions (critical concentration and critical temperature) was found to have higher value than the background non-critical sheer viscosity value $(0.8262 \mathrm{cP})$ at temperatures near critical. This indicated that the binary cyclohexane-phenol mixture has a higher intermolecular force at critical conditions. Therefore, less fluidity than the critical concentration at temperatures near above critical. Hence one could expect that thermal expansion coefficient at critical conditions to be lower than its noncritical backgrounds and density at critical conditions to be higher than its background.

\subsection{Thermal Expansion Coefficient}

For the mixture (cyclohexane - phenol) at critical concentration, the isobaric thermal expansion coefficient $\left(\alpha_{\mathrm{p}}\right)$, thermal isobaric critical expansion coefficient $\left(\alpha_{\mathrm{pc}}\right)$ and its background $\left(\alpha_{\mathrm{pb}}\right)$ were calculated by using equations (5) and (6). Fig. 3 shows a plot of density reciprocal versus temperature, with inset representing the linear fit equation of the drawn data. According to equation (6), $\alpha_{p}$ values at each temperature were calculated by multiplying the slope of the linear fit $\left(\left(\frac{\mathrm{d} \rho^{-1}}{\mathrm{~d} \mathrm{~T}}\right)=8 \times 10^{-4}\left(\mathrm{~cm}^{3} / \mathrm{gm} .{ }^{\circ} \mathrm{C}\right)\right)$ with the density at each temperature. 


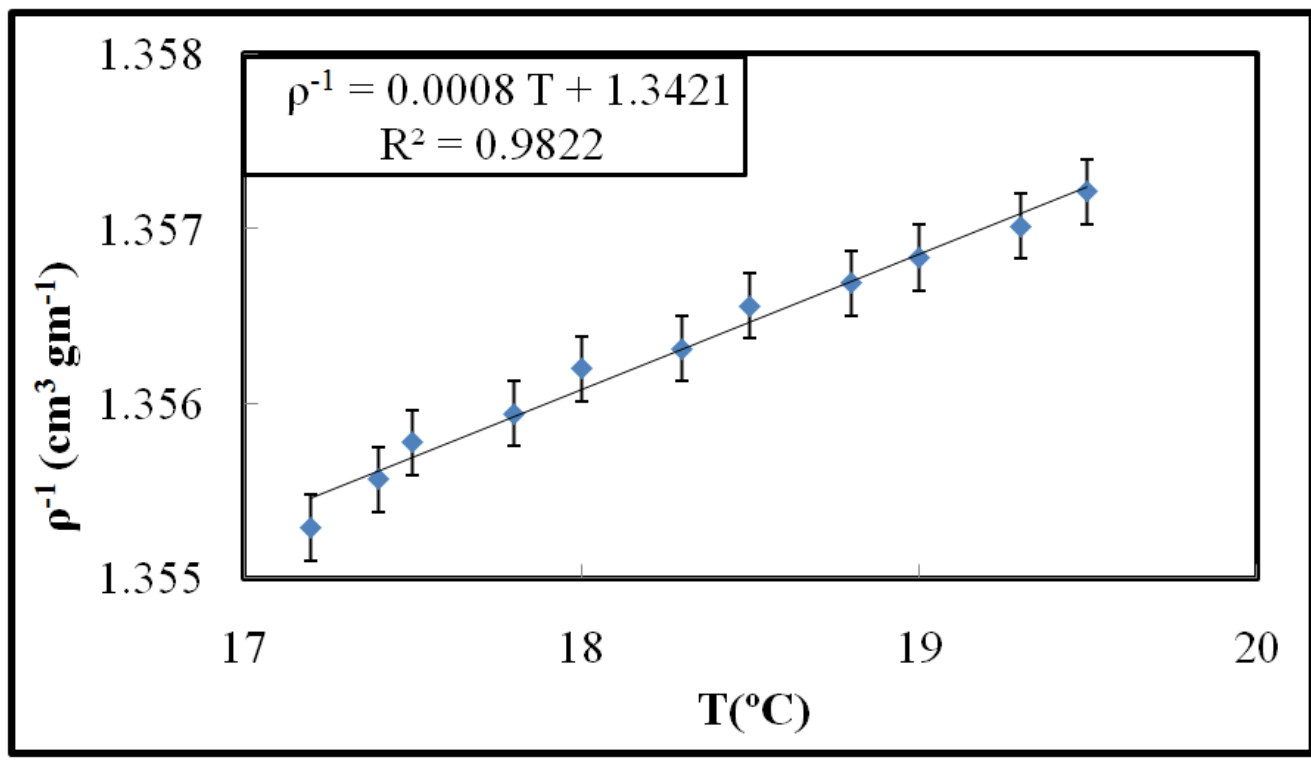

Figure 3. Density reciprocal $\left(\rho^{-1}\right)$ versus temperature $(T)$ above $T_{c}$ for the cyclohexane - phenol critical mixture. Linear equation for fitted data is shown in the insert.

From equation (5) $\left(\alpha_{p}=\alpha_{p c} \tau^{-\alpha}+\alpha_{p b}\right), \alpha_{p}$ versus $\tau^{-\alpha}$ was plotted (Fig. 4.) with $\alpha=0.11$ the critical thermal expansion coefficient at constant pressure $\left(\alpha_{\mathrm{pc}}\right)$ was found from the slope of linear fit $\left(\alpha_{\mathrm{pc}}=1.66 \times 10^{-6{ }^{\circ}} \mathrm{C}^{-1}\right)$, and the thermal background expansion coefficientat constant pressure $\left(\alpha_{\mathrm{pb}}\right)$ was found from the intercept $\left(\alpha_{\mathrm{pb}}=5.87 \times 10^{-4{ }^{\circ}} \mathrm{C}^{-1}\right)$. The lower expansion coefficient (lower than the background $\left.\alpha_{\mathrm{pb}}\right)$ observed at critical conditions $\left(\alpha_{\mathrm{pc}}\right)$ is due to higher intermolecular force confirmed by higher viscosity at critical conditions than its background.

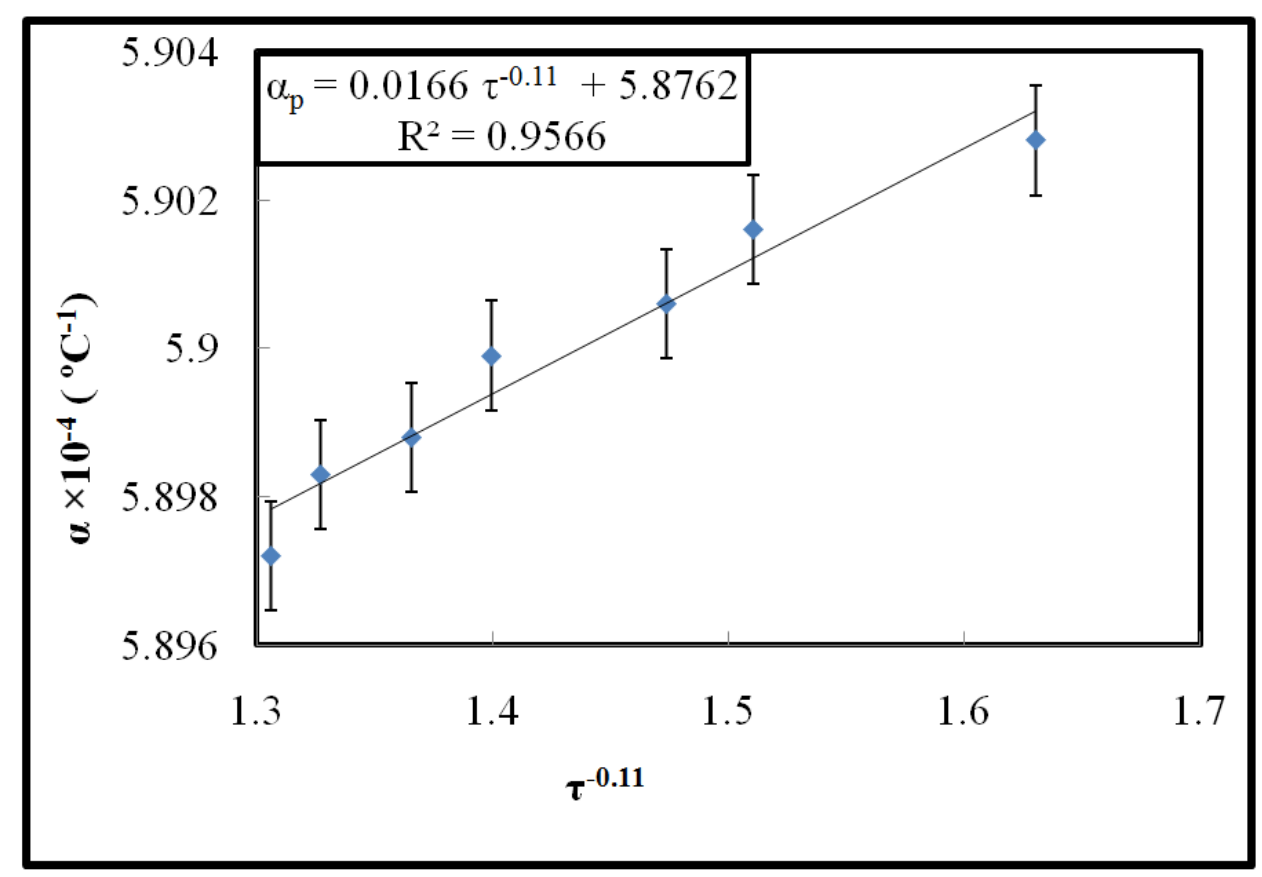

Figure 4. Cyclohexane - phenol critical mixture thermal expansion coefficient as function of $\tau^{-0.11}$. Linear equation for fitted data is shown in the insert. 


\subsection{The Noncritical Background For Mass Density}

At critical mixture concentration for cyclohexane-phenol, the mass density at the critical temperature $\rho_{\mathrm{c}}=0.7627 \frac{\mathrm{gm}}{\mathrm{cm}^{3}}$ was measured by pycnometer. This value is close to that for cyclohexane (see table 1) since cyclohexane weight concentration contributed $97.3 \%$ in the mixture.

In the asymptotic region close to critical point, like what observed for viscosity, mass density was also found to exhibit the behavior corresponds to a power law [17]. To determine mass density background $\rho_{0}$, the linear form of the mass density equation (2) $\left(\ln (\rho)=\ln \left(\rho_{\mathrm{o}}\right)-x_{\rho} v \ln (\tau)\right)$ was used. Fig 5. shows $\ln (\rho)$ against $\ln (\tau)$ with inset showing the linear equation of the linear fit for the data. From the slope of the linear equation, the mass density critical exponents were deduced ( $x_{\rho} v=0.0007$ and $x_{\rho}$ equals 0.00109 ; note that $v=0.64$ ). The noncritical mass density part $\rho_{0}=0.7357 \frac{\mathrm{gm}}{\mathrm{cm}^{3}}$ was found from linear equation intercept $\left(\ln \left(\rho_{0}\right)=-0.3068\right)$. As shown, the higher density observed at critical conditions are higher than their background. Indeed, at critical conditions we have observed higher viscosity than at non-critical background due to higher intermolecular forces between liquid molecules. This will lead the molecules of liquid mixture to slow down and compacted together with shorter intermolecular distances at critical. Hence higher density will be observed at critical conditions that at the non-critical background (at temperatures close to critical temperature).

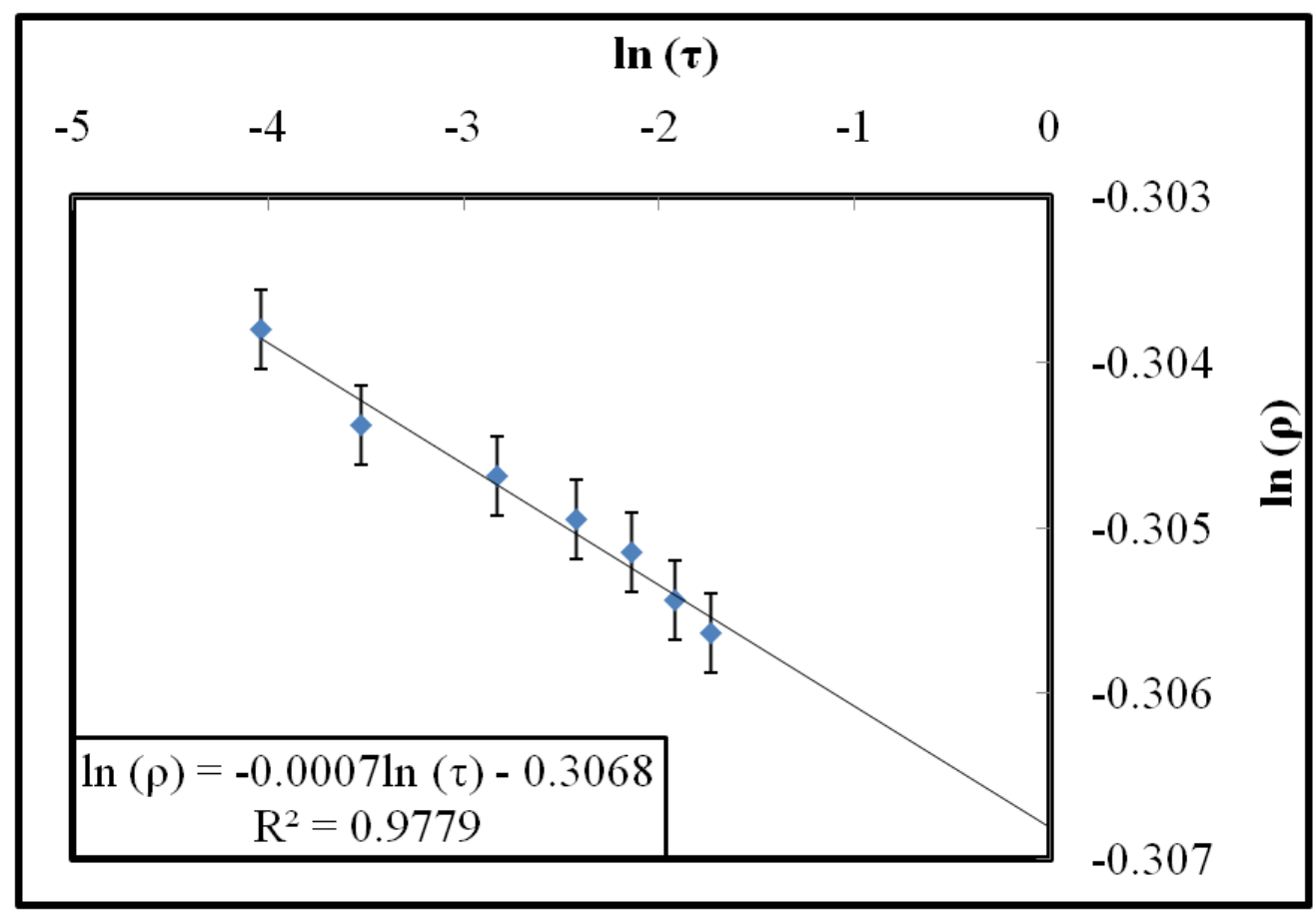

Figure 5. Plot of $\ln (\rho)$ versus $\ln (\tau)$ above the critical temperatur for the critical mixture cyclohexane phenol. Linear equation for fitted data is shown in the insert.

\subsection{Pressure Derivation For Critical Temperature}

The derivative of critical temperature with respect to pressure for the critical cyclohexane phenol mixture was calculated form equation (3)(two- scale factor universality equation): 
$R_{\xi}=\xi_{0}\left(\frac{\alpha \mathrm{T}_{\mathrm{c}} \alpha_{\mathrm{pb}}}{\mathrm{K}_{\mathrm{B}} \mathrm{T}_{\mathrm{c}}{ }^{\prime}}\right)^{\frac{1}{\mathrm{~d}}}=0.270(9)$

With $\propto=0.11, \mathrm{~d}=3$ and $\xi_{\mathrm{o}}=3.12 \AA[22-23]$, measured $\alpha_{\mathrm{pb}}=5.87 \times 10^{-4}{ }^{\circ} \mathrm{C}^{-1}$, and $\mathrm{T}_{\mathrm{c}}=$ $17^{\circ} \mathrm{C}$. The critical temperature derivative with respect to pressure $\left(\mathrm{T}_{\mathrm{c}}{ }^{\prime}=\frac{\mathrm{dT}_{\mathrm{c}}}{\mathrm{dP}}\right)$ was calculated and found to be $1.22 \times 10^{-4} \frac{\mathrm{K}}{\mathrm{Pa}}$.

\section{CONCLUSION}

The behavior of single liquids and binary liquid mixtures, at critical and near critical conditions, can be explained using different types of fitting, equations and polynomials. Many liquid parameters at critical conditions can be deduced such as viscosity, density, ultrasonic propagation, electrical conductivity, etc.

Behavior of cyclohexane-phenol binary liquid new mixture have been experimentally observed at and near critical conditions. Experiments were performed at different phenol weight concentrations and at different temperatures. In this paper, theoretical approximations for binary liquid mixture was used to deduce many parameters at critical and near critical conditions. Mode coupling approach and power law was used to find the shear viscosity (used to find critical concentration and temperature), noncritical part of shear viscosity, and mass density. In addition, The two - scale - factor universality that explains the critical phenomena of binary liquid mixtures was used to deduce other parameters like isobaric specific heat, isobaric and background isobaric thermal expansion coefficient.

The thermodynamic properties results of the liquid binary cyclohexane - phenol mixture that were measured or calculated are shown in table 2 .

Table 2. Measured and/or calculated parameters (summary table).

\begin{tabular}{|c|c|}
\hline Measured and/or calculated value (unit) & Results \\
\hline $\mathrm{x}_{\mathrm{C}}{ }^{*}$ : Phenol critical weight concentration $(\%)$ & $2.70 \%$ \\
\hline $\mathrm{T}_{\mathrm{c}}{ }^{*}$ : Critical temperature $\left({ }^{\circ} \mathrm{C}\right)$ & 17.0 \\
\hline$\eta^{* *}:$ Critical sheer viscosity at $(\mathrm{cP})$ & 0.9672 \\
\hline$\eta_{0}^{* *}:$ Sheer viscosity (Non critical part)(cP) & 0.8174 \\
\hline$\alpha_{\mathrm{pc}}{ }^{* *}$ : Isothermal expansion coefficient $\left({ }^{\circ} \mathrm{C}^{-1}\right)$ & $1.66 \times 10^{-6}$ \\
\hline$\alpha_{\mathrm{pb}}{ }^{* *}$ : Isobaric thermal expansion coefficient $\left({ }^{\circ} \mathrm{C}^{-1}\right)$ & $5.8701 \times 10^{-4}$ \\
\hline$x_{\rho} v^{* *}:$ Critical exponent & 0.0007 \\
\hline$x_{\rho}^{* *}:$ Critical exponent & 0.00109 \\
\hline$\rho_{0}{ }^{* *}$ Mass density (Noncritical part) $\left(\frac{\mathrm{gm}}{\mathrm{cm}^{3}}\right)$ & 0.7357 \\
\hline$\rho_{\mathrm{c}}{ }^{*}$ : Critical mixture density $\left(\frac{\mathrm{gm}}{\mathrm{cm}^{3}}\right)$ & 0.7627 \\
\hline $\mathrm{T}_{\mathrm{c}}{ }^{\prime * *}$ : Deviation of critical temperature Pressure $\left(\frac{K}{\mathrm{~Pa}}\right)$ & $1.22 \times 10^{-4}$ \\
\hline
\end{tabular}

Further future work, on such new binary liquid mixture (cyclohexane - phenol), can be performed like electrical conductivity, ultrasound velocity, optical properties, and dielectric properties. 


\section{REFERENCES}

[1] Ezekiel D D, Simphiwe M N, David A I \& and Eno E, (2012) "Density, Dynamic Viscosity and Derived Properties of Binary Mixtures of Methanol, Ethanol, n-Propanol, and n-Butanol with Pyridine at $\mathrm{T}=(293.15,303.15,313.15$ and 323.15)", K. Int. J. Electrochem. Sci., Vol. 7, pp11101 -11122.

[2] Rice O K, (1949) "Critical Phenomena in Binary Liquid Systems", Chemical Reviews, Vol. 44, pp6992.

[3] Musser M T, (2005)"Cyclohexanol and Cyclohexanone", Ullmann's Encyclopedia of Industrial Chemistry, Wiley-VCH, Weinheim .

[4] Abdelraziq I, (2005) "Critical behavior of the ultrasonic attenuation for the binary mixtures of benzene-coconut oil and hexane- $\beta, \beta^{\prime}$-dichloroethyl ether', The Journal of the Acoustical Society of America, Vol. 91, No. 4, pp716-722.

[5] Fixman M, (1962) "Viscosity of Critical Mixtures", Journal of Chemistry and Physics, Vol. 36, pp310-311.

[6] Domanska U \& Krolikowaska M, (2012) "Density and viscosity of binary mixtures of thiocyanate ionic liquids + water as a function of temperature", Journal of Solution Chemistry, Vol 41, No. 8, pp1422-1445.

[7] Easteal A J, (1980) "Tracer diffusion coefficients of tritiated water and acetonitrile in water + acetonitrile mixtures", Australian Journal of Chemistry, Vol. 33, No. 8, pp1667-1675.

[8] Gowrisankar M, Venkateswarlu P, Siva Kumar K \& Sivarambabu S, (2012) "Thermodynamics of amine + ketone mixtures 3.volumetric, speed of sound data and viscosity at (303.15 and 308.15K) for the binary mixtures of N,N-dimethylaniline + propiophenone, p-methylacetophenone, pchloroacetophenone", Journal of Molecular Liquids, Vol. 173, pp172-179.

[9] Emila M, Mirjana L, Ivona R, Slobodan P \& Bojan D, (2010) "Viscosity of the binary systems 2methyl-2-propanol with n-alkanes at $\mathrm{T}=(303.15,308.15,313.15,318.15$ and 323.15$) \mathrm{K}$ : prediction and correlation - new unifac-visco interaction parameters", Fluid Phase Equilibria, Vol. 299, pp191197.

[10] Abdelraziq I, Musameh S \& Abu-Jafar M, (1997) "Shear viscosity anomaly near the critical binary system of nitrobenzene-N-heptane", Bethlehem University Journal, Vol. 16, pp70-78.

[11] Kestin J, Ezzat H K \& Robert J. C, (1981) "Tables of the dynamic and kinematic viscosity of aqueous $\mathrm{NaCl}$ solutions in temperature range $20-150^{\circ} \mathrm{C}$ and the pressure range $0.1-35 \mathrm{MPa}$, Journal of Physical and Chemical Reference, Vol. 10, No. 1, pp57-59.

[12] Babavali Sk F, Sarma NT , Srinivasu Ch 3 , Vijay Kumar1 B, \& Narendra K, (2018) " Thermo theoretical ultrasonic studies in binary liquid mixtures containing heterocyclic aromatic compound quinoline with 1-butanol at temperatures T= (303.15, 308.15, 313.15 and 318.15) K", Res. J. Pharm., Biol. Chem. Sci, Vol. 9, No. 2, pp643-649.

[13] Al-Arfaj A A, Kacem R B H, Snoussi L, Vrinceanu N, Alkhaldi M A, Alzamel N O \& Ouerfelli N, (2017) "Correlation Analysis of the viscosity Arrhenius-type equations parameters for some binary liquids mixtures", Mediterranean Journal of Chemistry, Vol. 6, No. 2, pp23-32.

[14] Niarat T, Musameh S \& Abdelraziq I, (2014) "Temperature-dependence of olive oil viscosity", Materials Science, Vol. 11, No. 7, pp233-238. 
International Journal of Recent Advances in Physics (IJRAP) Vol.8, No.1, February 2019

[15] Secco R, deBruyn J \& Kostic M, (2014) Measurement, Instrumentation, and Sensors Handbook, 2nd Edition spatial, Chapter 46, Fluid Viscosity Measurement, J.G. Webster and E. Halit. CRC Press. ISBN: 978-1-4398-4888-3.

[16] Perl R \& Ferrell R A, (1972) "Some topics in nonequilibrium critical phenomena", Physical Review,Vol. A6, pp23-58.

[17] Klein H \& Woermann D, (1978) "Analysis of light-scattering and specific heat data of binary liquid mixtures in terms of the two-scale-factor universality" Journal of Physical Chemistry, Vol. 82, pp1084-1086.

[18] Heller P \& Benedek G B (1962) "Nuclear Magnetic Resonance in $\mathrm{MnF}_{2}$ Near the Critical Point", Phys. Rev. Lett., Vol. 8, pp428-432.

[19] Thompson D R \& Rice O K, (1964) "Shape of the Coexistence Curve in the Perfluoromethyl cyclohexane-Carbon Tetrachloride System II. Measurements Accurate to 0.0001 ". J. Am. Chem. Soc, Vol. 86, No. 17, pp3547-3553.

[20]Cheung A, (2011) "Phase Transitions and Collective Phenomena" Lecture Notes, pp5-9.

[21] Qasim M \& Darwish N, (2013) "Prediction of stability limits and critical conditions of binary liquid mixtures containing nitro-methane using the NRTL model", Fluid Phase Equilibria, Vol. 360,pp146155.

[22] Hohenberg P C, Aharony A, Halperin B I \& Siggia E D, (1976) "Two - scale - factor universality and the renormalization group", Physical Review B, Vol. 13, No. 7, pp2986-2987.

[23] Abdelraziq I, (2003) "Two - Scale - Factor Universality of Binary Liquid Critical Mixtures", Pakistan Journal of Applied Science, Vol. 3, pp142-144.

[24] Anderson D L, (1989) Theory of the Earth, Boston, MA, Blackwell Scientific Publications, ISBN 0865423350 .

[25] Colette S, Elizabeth H, Martha G \& Andrea P, (2003) Toxicological Review of Cyclohexane, United States Environmental Protection Agency, Washington.

[26] Frumkin H \& Gerberding J, (2008) Toxicologlcal Profile for Phenol, United States Department of Health And Human Services, pp13-15.

[27] Seeton C J, (2006) "Viscosity-temperature correlation for liquids", Tribology Letters, Vol. 22, No. 1, pp67-78. 